\title{
Niveles séricos de proteínas y peso vivo en llamas (Lama glama) pastoreadas en praderas nativas de Curahuara De Carangas, Oruro
}

(cc) (1) (\$) (2)

\author{
Serum protein levels and live weight in llamas (Lama glama) grazed in native grasslands \\ of Curahuara De Carangas, Oruro
Níveis séricos de proteína e peso vivo em lhamas (Lama glama) pastados em pastagens nativas de Curahuara De Carangas, Oruro

Marleni Julia Ramos Choque mvz.leni_985@hotmail.com

Santiago Copa Quispe copasanty@gmail.com

Jaime Fidel Cahuana Mollo Jfc_966@hotmail.com

Universidad Pública de El Alto, Bolivia

\section{RESUMEN}

El crecimiento y la nutrición de llamas se afectan mutuamente. El estudio tuvo como objetivo determinar los niveles séricos de proteínas y peso vivo en llamas (Lama glama) pastoreados en praderas nativas de la zona Huacullani comunidad Jilahuta Manasaya, Municipio Curahuara de Carangas Provincia Sajama, Oruro. Se emplearon 77 llamas distribuidos por categorías de edad y sexo, se tomaron muestras de $8 \mathrm{ml}$ de sangre de la vena yugular, el suero se obtuvo por centrifugación en noviembre, enero y marzo; los análisis de laboratorio de proteína total, albúmina, bilirrubina total y directa se realizaron por el método colorimétrico, la urea por el método enzimático específico, la creatinina por el método colorimétrico cinético, globulina por diferencia. Los resultados fueron: proteína total $6,54 \pm 2,23 \mathrm{~g} / \mathrm{dl}$ influida por factores meses $y$ edad $(\mathrm{P}<0,01)$; albúmina $3,75 \pm 1,22 \mathrm{~g} / \mathrm{dl}$ afectada por meses, sexo y categoría de edad $(\mathrm{P}<0,01)$; globulina 2,78 $\pm 2,73 \mathrm{~g} / \mathrm{dl}$ influida por meses, entre otras. Los resultados sobre los niveles séricos de proteínas totales, albúmina, globulina y urea se encuentran dentro de los parámetros referenciales; sin embargo, el peso vivo de los animales es relativamente bajo.

Palabras clave: Niveles séricos; proteínas; llamas (Lama glama); crecimiento; nutrición; pradera nativas

\begin{abstract}
The growth and nutrition of llamas affect each other. The objective of the study was to determine the serum protein levels and live weight in llamas (Lama Glama) grazed in native meadows of the Huacullani area, Jilahuta Manasaya community, Curahuara de Carangas Municipality, Sajama Province, Oruro. 77 llamas distributed by age and sex categories were used, samples of $8 \mathrm{ml}$ of blood were taken from the jugular vein, the serum was obtained by centrifugation in November, January and March; Laboratory analyzes of total protein, albumin, total and direct bilirubin were performed by the colorimetric method, urea by the specific enzymatic method, creatinine by the kinetic colorimetric method, globulin by difference. The results were: total protein $6.54 \pm 2.23 \mathrm{~g} / \mathrm{dl}$ influenced by factors months and age ( $P<0.01)$; albumin $3.75 \pm 1.22 \mathrm{~g} / \mathrm{dl}$ affected by months, sex and age category $(\mathrm{P}<0.01)$; globulin $2.78 \pm 2.73 \mathrm{~g} /$ $\mathrm{dl}$ influenced by months, among others. The results on the serum levels of total proteins, albumin, globulin and urea are within the referential parameters; however, the live weight of the animals is relatively low.
\end{abstract}

Key words: Serum levels; proteins; llamas (Lama glama); increase; nutrition; native meadow

Alfa, Revista de Investigación en Ciencias Agronómicas y Veterinarias Vol. 4, JNo. 10, Enero - Abril 2020 


\section{RESUMO}

0 crescimento e a nutrição das lhamas se afetam proporcionalmente. 0 objetivo do estudo foi determinar os níveis séricos de proteína e o peso vivo em lhamas (Lama glama) pastados em prados nativos da área de Huacullani, comunidade Jilahuta Manasaya, município de Curahuara de Carangas, província de Sajama, Oruro. Foram utilizados 77 lhamas, distribuídos por idade e sexo, das quais, foram tiradas amostras de $8 \mathrm{~mL}$ de sangue da veia jugular. 0 soro foi obtido em novembro, janeiro e março pela sua centrifugação; as análises laboratoriais de proteína total, albumina, bilirrubina total e direta foram realizadas pelo método colorimétrico; A ureia pelo método enzimático específico; a creatinina pelo método colorimétrico cinético; e a globulina por diferença. Os resultados foram: proteína total 6,54 $\pm 2,23 \mathrm{~g} / \mathrm{dL}$ influenciada por fatores meses e idade $(\mathrm{P}<0,01)$; albumina $3,75 \pm$ $1,22 \mathrm{~g} / \mathrm{dl}$ afetada por meses, sexo e categoria de idade ( $\mathrm{P}<0,01)$; globulina 2,78 $\pm 2,73 \mathrm{~g} / \mathrm{dl}$ influenciada por meses, entre outros. Os resultados sobre os níveis séricos de proteínas totais, albumina, globulina e ureia estão dentro dos parâmetros referenciais; no entanto, o peso vivo dos animais é relativamente baixo.

Palavras-chave: Níveis séricos; proteínas; lhamas (Lama glama); crecimento; nutrição; pastagens nativas

\section{INTRODUCCIÓN}

La deficiencia nutricional es una de las razones por las cuales ocurren desórdenes metabólicos, el médico veterinario para reconocerlo puede calcular y balancear la ración ingerida por los animales y realizar estudios de los nutrientes requeridos por el animal. Sin embargo, hay variación de los nutrientes de las plantas, técnicas de alimentación, pérdidas de nutrientes durante su almacenamiento, interacción de nutrientes en el tracto digestivo, condiciones individuales, entre otras, lo cual de igual forma debe ser considerado. Para evitar estas desventajas se han establecido parámetros para determinar el nivel de ciertos metabolitos sanguíneos y que forman parte del test de perfil metabólico (Scholz, 2001).

Con el uso de las pruebas de química sanguínea es posible diferenciar entre una enfermedad predominantemente hepatocelular o colestática y evaluar la severidad y cronicidad de una condición. Por ejemplo los perfiles metabólicos son usados en el ganado bovino para ayudar en el diagnóstico de problemas metabólicos y enfermedades de la producción e identificar vacas superiores.

En las grandes especies existe dificultad en la realización de la exploración clínica correcta de la glándula. Por eso se pensó que estudiar el hígado por medio de pruebas de laboratorio como las mencionadas, brinda una visión instantánea de su funcionamiento, en especial, si existe una descompensación en su trabajo metabólico normal.

La información que se tiene sobre los valores bioquímicos en camélidos especie llama (Lama glama) en Bolivia es muy escasa. Cuando se precisa conocer las concentraciones de estos valores no hay otra alternativa que recurrir a los manuales clásicos de información veterinaria y/o publicaciones, tesis de grado, de trabajos realizados en camélidos de otros países de condiciones climáticas y de manejo muy diferentes a las acostumbradas en el país.

Los objetivos del estudio fueron evaluar los niveles séricos de proteínas y peso vivo en llamas (Lama glama) pastoreados en praderas nativas de la zona Huacullani comunidad Jilahuta Manasaya, Municipio Curahuara de Carangas Provincia Sajama, Oruro. Además de determinar los niveles séricos de proteína total, albúmina, globulina y urea de llamas pastoreadas en praderas nativas según meses, sexo y categoría de edad; los niveles séricos de creatinina, bilirrubina directa y bilirrubina total de llamas pastoreadas en praderas nativas según meses, sexo y categoría de edad $\mathrm{y}$ el peso vivo de llamas pastoreadas en praderas nativas según meses, sexo y categoría de edad. 
La importancia de los camélidos y su cuidado radican en que de 160 mil personas (tres personas de las 53078 familias) se dedican a la crianza de alpacas y llamas; por otro lado son 6900 personas las empleadas en la industria textil y de confecciones y se estima que operan en actividades de comercialización alrededor de 500 intermediarios, lo cual hace un total de 170 mil empleos directos generados por el sistema de los camélidos, representando el $1,5 \%$ del total del empleo generado en el país y ratificando su importancia social (FAO, 2005).

Población actual de camélidos en Bolivia, las áreas de mayor concentración de camélidos sudamericanos se encuentra en el departamento de Oruro con 1.401.634 cabezas (59\%), seguido por La Paz con 475.637 cabezas (20\%), llegando a ocupar estos departamentos el 79\% del total nacional que asciende en el país a 2.363 .659 cabezas. Posteriormente esta Potosí con 374.500 cabezas (16\%), Cochabamba con 105.793 cabezas (5\%), Chuquisaca con $39.113(0,1 \%)$ y por último el departamento de Tarija con $2.900(0,1 \%)$ (SENASAG-PAITITI 2010).

\section{MATERIALES Y MÉTODOS}

\section{Localización del área de investigación}

La investigación se realizó en la zona Huacullani de la comunidad Jilahuta Manasaya de la primera sección municipal Curahuara de Carangas de la Provincia Sajama del Departamento de Oruro, ubicadas entre las latitudes sur $17^{\circ} 35^{\prime}$ a $18^{\circ} 17^{\prime}$ entre las longitudes oeste $68^{\circ} 20^{\prime}$ a $69^{\circ} 68^{\prime}$ y a 3.976 msnm.

Está ubicada en el extremo noreste del territorio departamental en el territorio del Parque Nacional Sajama, limita al norte con los municipios de Calacoto y Callapa de la Provincia Pacajes del Departamento de La Paz, al sur con el Municipio de Turco de la Provincia Sajama; al Este con el Municipio de San Pedro de Totora de la Provincia de San Pedro de Totora del Departamento de Oruro y al oeste con la República de Chile.

El municipio, tiene una extensión superficial de $2.786 \mathrm{~km}^{2}$, representando el $48 \%$ para toda el área de la Provincia Sajama y el 5,27\% del Departamento de Oruro.

\section{Aspectos físico naturales de la zona de estudio}

La zona corresponde a la fisiográfica de la Cordillera Occidental o volcánica, localizada entre la serranía Saucarí hacia el Oriente y la Cordillera Occidental, ramal Cordillera de Pacajes hacia el Occidente. Se caracteriza por su topografía muy accidentada, constituida por materiales de origen volcánico, alta fragilidad a los procesos de erosión y con escasa cobertura vegetal.

Fisiográficamente, presenta serranías interplánicas, correspondientes a las serranías de Saucarí, conformada por cerros, colinas, serranías y altas mesetas, integradas con llanuras extensas altas y bajas (ERTSGEOBOL, 1978; Gobierno Municipal de Curahuara de Carangas, 2007).

La topografía es irregular y con diferencias notables, presentando áreas muy a extremadamente escarpadas, especialmente las altas montañas; mientras que en las áreas labradas por la acción fluvioglaciar, como en los valles y llanuras, el relieve y la topografía son más uniformes.

\section{Características del ecosistema de la zona de estudio}

En virtud a la micro regionalización, en el municipio, se distinguen tres grandes unidades morfográficas (visión espacial), las 
mismas que son: Alta Montaña (Suni uta), Ladera baja o Piedemonte Local (Chacarismo) y Plano de Valle (Pampa Uta). Unidades que antrópicamente son utilizadas para diferentes propósitos en atención a sus características: edáficas, agrostológicas, hidrológicas, climáticas, etc.

Pese a la escasa cobertura de los servicios meteorológicos en el Departamento de Oruro, el Estudio del Sistema TDPS (1993), a través de varios trabajos, ha logrado definir que el clima en la región ubicada por el municipio de Curahuara de Carangas, se clasifica como semiárido árido y frío, con otoños, inviernos y primavera secos.

La precipitación pluvial media anual varía entre 300 hasta $400 \mathrm{~mm}$, caracterizada por eventos ocurridos durante los meses de noviembre hasta marzo, mientras que los meses de otoño e invierno corresponden al período de estiaje. Frecuentemente las precipitaciones ocurren en forma intensa y de corta duración.

Las precipitaciones en forma de nieve o granizada, muestran una tendencia a aumentar de oeste a este, este incremento se da por el sentido geográfico y se debe a la influencia de los vientos predominantes que van en el sentido ya indicado.
En el área del Parque Nacional Sajama, la precipitación media anual es de aproximadamente $327 \mathrm{~mm}$ y la tasa de evapotranspiración por la alta insolación está alrededor de 3,5 a 4 mm/día.

\section{Materiales}

En el material biológico se usó para la muestra suero sanguíneo; semovientes se emplearon un total de 77 llamas seleccionadas por categoría de edad entre hembras y machos de los cuales, 59 hembras y 18 machos. En el Material de campo se usó Termómetros rectal ${ }^{\circ} \mathrm{C}$, algodón, bolsas de polietileno, marcador indeleble, overol, botas rubber, guantes de goma, sogas de fibra de llama, tablero, libreta de campo y bolígrafos, cámara fotográfica, aretes metálicos, areteador metálico, alcohol yodado

\section{Materiales para colección de sangre}

Agujas vacutainer \# 21 x $1 / 2$; Tubos vacutainer de $10 \mathrm{ml}$; Holders (Adaptador para tubo de ensayo); Marcador indeleble para la identificación de las muestras; Masquin; Gradillas para tubos de ensayo; Gradillas para tubos eppendorf; Guantes quirúrgicos; $\mathrm{y}$ Conservadora de plastoform. 
Cuadro 1. Material de laboratorio

\begin{tabular}{|c|c|c|}
\hline $\begin{array}{l}\text { Materiales para análisis de } \\
\text { suero sanguíneo }\end{array}$ & Equipos & Reactivos \\
\hline Tubos Fisher $12 \times 15 \mathrm{~mm}$ & $\begin{array}{l}\text { Balanza de precisión capacidad } \\
200 \mathrm{~kg}\end{array}$ & $\begin{array}{l}\text { Kit para Proteína Total: Ion } \\
\text { cúprico }\end{array}$ \\
\hline Tubos ependorf 1.5 a $2 \mathrm{ml}$ & Centrifugadora de 24 tubos & $\begin{array}{l}\text { Kit para Albúmina : Tetrabromo } \\
\text { Cresolsulfon Ftaleína }\end{array}$ \\
\hline Probetas de 100 y $50 \mathrm{ml}$ & $\begin{array}{l}\text { Analizador químico } \\
\text { semiautomático stat fax } 1908\end{array}$ & $\begin{array}{l}\text { Kit para Urea: Dióxido de } \\
\text { Carbono }\end{array}$ \\
\hline $\begin{array}{l}\text { Pipetas de vidrio } 1 \mathrm{ml}, 2 \mathrm{ml}, 5 \mathrm{ml} \text {, } \\
10 \mathrm{ml}\end{array}$ & $\begin{array}{l}\text { Vortex (L-VM 1000) con cabezal } \\
\text { de una copa para un tubo }\end{array}$ & $\begin{array}{l}\text { Kit para Creatinina: Acido } \\
\text { Pícrico }\end{array}$ \\
\hline Tips & Horno esterilizador $50^{\circ}$ a $300^{\circ} \mathrm{C}$ & $\begin{array}{l}\text { Kit para Bilirrubina: Ácido } \\
\text { Sulfanílico Diazotado }\end{array}$ \\
\hline $\begin{array}{l}\text { Gradillas para eppendorf } \\
\text { Pipeta Pasteur }\end{array}$ & $\begin{array}{l}\text { Baño maría de } 25^{\circ} \mathrm{C} \text { a } 100^{\circ} \mathrm{C} \\
\text { Autoclave } 103 \text { kpa de presión } \\
\text { alcanza a } 121^{\circ} \mathrm{C}\end{array}$ & \\
\hline Probeta Graduada & $\begin{array}{l}\text { Balanza analítica } 0.008 \text { g a } 150 \mathrm{~g} \\
\text { Refrigerador }-30^{\circ} \mathrm{C} \text { a } 38^{\circ} \mathrm{C} \\
\text { Micropipetas de } 10 \mathrm{ul}, 20 \mathrm{ul}, 50 \mathrm{ul}, \\
\text { 100ul, 200ul }\end{array}$ & \\
\hline
\end{tabular}

\section{Control de peso vivo de las llamas}

Concluido el proceso de adiestramiento de animales y previo inicio del trabajo de investigación se tomó el registro de peso vivo de las llamas, las mediciones de cada animal de estudio, con la balanza de precisión tipo plataforma, cada 60 días.

\section{Toma de muestra sanguínea}

Se obtuvo de 6 a $8 \mathrm{ml}$ de la sangre en condiciones estériles. Se utilizó agujas N ${ }^{0} 21$ $11 / 2$ pulgadas de un solo uso (posteriormente guardándolas en frascos de plástico evitando contaminar el medio ambiente), tubos al vació de $10 \mathrm{ml}$ con tapa roja, utilizando el adaptador para unir la aguja con el tubo de ensayo. Se limpió y desinfectó con algodón y alcohol yodado el sitio de punción. Se realizó la extracción de sangre mediante punción de un vaso sanguíneo (vena yugular).
Seguidamente los tubos fueron identificados y codificados con números correlativos de extracción y arete del animal, registrándose en la planilla de campo la categoría de edad, sexo y fecha de muestreo. Posteriormente acomodados en gradillas inclinadas a $45^{\circ}$ grados. Para el transporte de las muestras se utilizó conservadoras de plastoformo.

\section{Método de laboratorio}

Las muestras fueron remitidas de acuerdo a recomendaciones técnicas desde la comunidad de Jilahuta Manasaya hacia la ciudad de La Paz hasta el laboratorio "LACLIVEA" de la Carrera de Medicina Veterinaria y Zootecnia de la Universidad Pública de El Alto.

\section{Obtención de suero}

Una vez obtenida la muestra se procedió 
a centrifugar los tubos sin anticoagulante durante 10 minutos a $2500 \mathrm{rpm}$. Posteriormente se realizó la separación del suero sanguíneo empleando una micropipeta, para depositar el suero en tubos eppendorf. Los sueros sanguíneos se conservaron en congelación $-4^{\circ} \mathrm{C}$.

\section{Análisis de los componentes bioquímicos}

El procedimiento del análisis se realizó de acuerdo a las técnicas de cada kit, previo control de calidad de exactitud de los procedimientos. En tanto el principio de cada metabolito se observa en consecuencia se tomó nota de los datos en la planilla de laboratorio.

\section{Análisis de proteína total}

Se clasifico los tubos blancos, estándar, control y pacientes, se transfirió el agente en cada tubo de colorimétrico aumentando la muestra en cada tubo con ayuda del micropipeta, mezclando homogéneamente y se registraron los datos correspondientes. Los enlaces peptídicos de las proteínas reaccionan con el ion cúprico, medio alcalino, para dar un complejo violeta con máximo absorción a 540 nm cuya intensidad es proporcional a la concentración de proteínas totales en la muestra.

\section{RESULTADOS Y DISCUSIÓN}

Las proteínas son los principales constituyentes del cuerpo animal y esencial para la reparación celular y procesos de síntesis. La deficiencia proteica en la dieta con lleva a un agotamiento de las reservas en la sangre, hígado y músculos, predisponiendo al animal a una variedad de cuadros muchos de ellos fatales (San Martin, 1999).

\section{Niveles séricos de proteína total de llamas pastoreadas en praderas nativas según meses, sexo y categoría de edad}

La media general de los niveles séricos de proteína total obtenidos fue de $6,54 \pm 2,23$ $\mathrm{g} / \mathrm{dl}$ con extremos de $4,31 \mathrm{~g} / \mathrm{dl}$ a $8,77 \mathrm{~g} / \mathrm{dl} \mathrm{de}$ llamas pastoreadas en praderas nativas en la comunidad Jilahuta Manasaya de Curahuara de Carangas según meses, sexo y categoría de edad. (Tabla 1).

Tabla 1. Niveles séricos de proteína total de llamas pastoreadas en praderas nativas

\begin{tabular}{|c|c|c|c|c|c|c|}
\hline Meses & Sexo & $\begin{array}{c}\text { Categoría de } \\
\text { edad }\end{array}$ & $\mathbf{n}$ & Media $\pm 2 S D(g / d l)$ & $\begin{array}{l}\text { Min } \\
\text { (g/dl) }\end{array}$ & $\begin{array}{l}\text { Max } \\
(\mathrm{g} / \mathrm{dl})\end{array}$ \\
\hline \multirow{6}{*}{ Noviembre } & \multirow{4}{*}{ Hembra } & A & 10 & $5,65 \pm 0,42$ & 5,40 & 6 \\
\hline & & B & 19 & $6,22 \pm 1,64$ & 4,50 & 7,70 \\
\hline & & $\mathrm{C}$ & 10 & $6,01 \pm 1,26$ & 5 & 7,50 \\
\hline & & $\mathrm{D}$ & 20 & $6,17 \pm 1,20$ & 5,10 & 7,30 \\
\hline & \multirow{2}{*}{ Macho } & A & 10 & $5,65 \pm 1,04$ & 4,50 & 6,30 \\
\hline & & $\mathrm{C}$ & 8 & $5,68 \pm 1,58$ & 4,20 & 6,60 \\
\hline
\end{tabular}




\begin{tabular}{|c|c|c|c|c|c|c|}
\hline Meses & Sexo & $\begin{array}{c}\text { Categoría de } \\
\text { edad }\end{array}$ & $\mathbf{n}$ & Media $\pm 2 S D(g / d l)$ & $\begin{array}{l}\text { Min } \\
\text { (g/dl) }\end{array}$ & $\begin{array}{l}\text { Max } \\
(\mathrm{g} / \mathrm{dl})\end{array}$ \\
\hline \multirow{6}{*}{ Enero } & \multirow{4}{*}{ Hembra } & $\mathrm{A}$ & 9 & $5,98 \pm 1,14$ & 3,70 & 6,60 \\
\hline & & B & 20 & $6,97 \pm 2,24$ & 5,40 & 11,10 \\
\hline & & $\mathrm{C}$ & 9 & $6,14 \pm 1,86$ & 4,40 & 7,90 \\
\hline & & $\mathrm{D}$ & 18 & $6,68 \pm 1,24$ & 5,90 & 8,10 \\
\hline & \multirow{2}{*}{ Macho } & A & 8 & $6,10 \pm 0,68$ & 5,40 & 6,40 \\
\hline & & $\mathrm{C}$ & 8 & $6,33 \pm 1,34$ & 5,50 & 7,60 \\
\hline \multirow{6}{*}{ Marzo } & \multirow{4}{*}{ Hembra } & A & 9 & $6,27 \pm 0,86$ & 5,90 & 7,30 \\
\hline & & B & 20 & $7,35 \pm 2,78$ & 5,60 & 10,50 \\
\hline & & $\mathrm{C}$ & 10 & $6,75 \pm 1,34$ & 5,20 & 7,80 \\
\hline & & $\mathrm{D}$ & 21 & $7,45 \pm 2,92$ & 3,70 & 10,10 \\
\hline & \multirow{2}{*}{ Macho } & A & 9 & $6,90 \pm 3,68$ & 5 & 11,20 \\
\hline & & $\mathrm{C}$ & 7 & $7,60 \pm 2,06$ & 6,70 & 9,10 \\
\hline
\end{tabular}

El análisis de varianza (tabla 2), muestra que los factores meses y edad influyen significativamente $(\mathrm{P}<0,01)$ sobre la concentración de proteínas totales en suero sanguíneo de llamas. El coeficiente de variación de 14,79\%, indica que los datos obtenidos son confiables.

Tabla 2. Análisis de varianza de los niveles séricos de proteínas totales de llamas pastoreadas en praderas nativas según meses, sexo y categoría de edad.

\begin{tabular}{lrrrrr}
\hline \multicolumn{1}{c}{ Fuente de Variación } & GL & \multicolumn{1}{c}{ S C } & \multicolumn{1}{c}{ C M } & \multicolumn{1}{c}{ FV } & Pr > F \\
\hline Meses & 2 & 49,26486 & 24,63243 & 26,3 & $0,0001^{* *}$ \\
Sexo & 1 & 1,55163 & 1,55163 & 1,66 & 0,1995 NS \\
Meses x Sexo & 2 & 3,69519 & 1,84759 & 1,97 & $0,1417 \mathrm{NS}$ \\
Categoría de edad & 3 & 20,27351 & 6,75783 & 7,21 & $0,0001^{* *}$ \\
Mes x Categoría de edad & 6 & 3,55851 & 0,593086 & 0,63 & $0,7036 \mathrm{NS}$ \\
Sexo x Categoría de edad & 1 & 0,00011 & 0,00011 & 0,00 & $0,9910 \mathrm{NS}$ \\
Mes x Sexo x Categoría de edad & 2 & 0,36911 & 0,18455 & 0,20 & $0,8213 \mathrm{NS}$ \\
Error & 207 & 193,88890 & 0,93666 & & \\
Total & $\mathbf{2 2 4}$ & $\mathbf{2 7 4 , 0 8 3 8 2}$ & & & \\
\hline
\end{tabular}

C.V. $14,79 \%$

En la investigación se acepta la Ho para el factor sexo por presentar resultados estadísticamente similares y se rechaza para los factores meses y categoría de edad por presentar los resultados estadísticamente diferentes.
En la zona de estudio durante el mes noviembre por las condiciones climáticas se presenta la época seca, donde los pastos nativos se encuentran lignificados en el estado de madurez fisiológica, que se caracterizan por la baja calidad nutritiva y escasa 
degradabilidad. Bajo esta situación las llamas alimentadas con estos pastos son afectados en

Durante el mes de enero que se caracteriza por un clima lluvioso los pastos nativos se encuentran en la etapa de crecimiento y tiernos con la consecuente mejora la calidad nutritiva y digestibilidad que determina los niveles séricos de proteínas totales se incrementen. En el mes de marzo los pastos nativos de encuentran en estado fenológico de floración que se caracteriza por su alto contenido nutritivo y digestibilidad que influye a que los niveles séricos de las proteínas totales de llamas sean altos.

La buena disponibilidad de la calidad y cantidad de proteínas totales digerible en los pastos, es muy importante para la proliferación de los microorganismos en el compartimiento 1 (C1) y el compartimiento 2 (C2) de las llamas, de manera que a mayor proliferación de microorganismos dará como resultado mayores concentraciones séricas de proteínas totales.

El tipo de ración afecta la digestibilidad de proteína de las raciones (Choque 2009). los niveles de proteínas totales séricas que en su generalidad son inferiores a los parámetros. Los microorganismos del rumen tiene un efecto nivelador sobre el aporte de proteína al animal; suplementan cualitativamente $\mathrm{y}$ cuantitativamente las proteínas de los alimentos groseros de mala calidad (Donald, 1999).

Los resultados de la concentración sérica de proteína total obtenida en el presente estudio, muestran valores similares a los encontrados por Murray (1998), de 4,7 g/dl a $7,3 \mathrm{~g} / \mathrm{dl}$. Otros trabajos realizados en plasma sanguíneo reportan valores que se encuentran dentro los rangos obtenidos en este estudio: Coaquira (2005) en llamas machos de 6,01 g/dl a 6,65 g/dl, Ajata (2006) de 7,05 g/dl a 7,83 g/dl, Ticona (2009) de $5,43 \mathrm{~g} / \mathrm{dl}$ a $9,03 \mathrm{~g} / \mathrm{dl}$ y Choque (2009) de 5,9 $\mathrm{g} / \mathrm{dl}$.

Las diferencias en los niveles séricos de proteínas totales en las llamas están influidas por el estado fenológico de los pastos, las mismas que están relacionadas con las características climáticas particulares que se presentan en los diferentes meses del año.

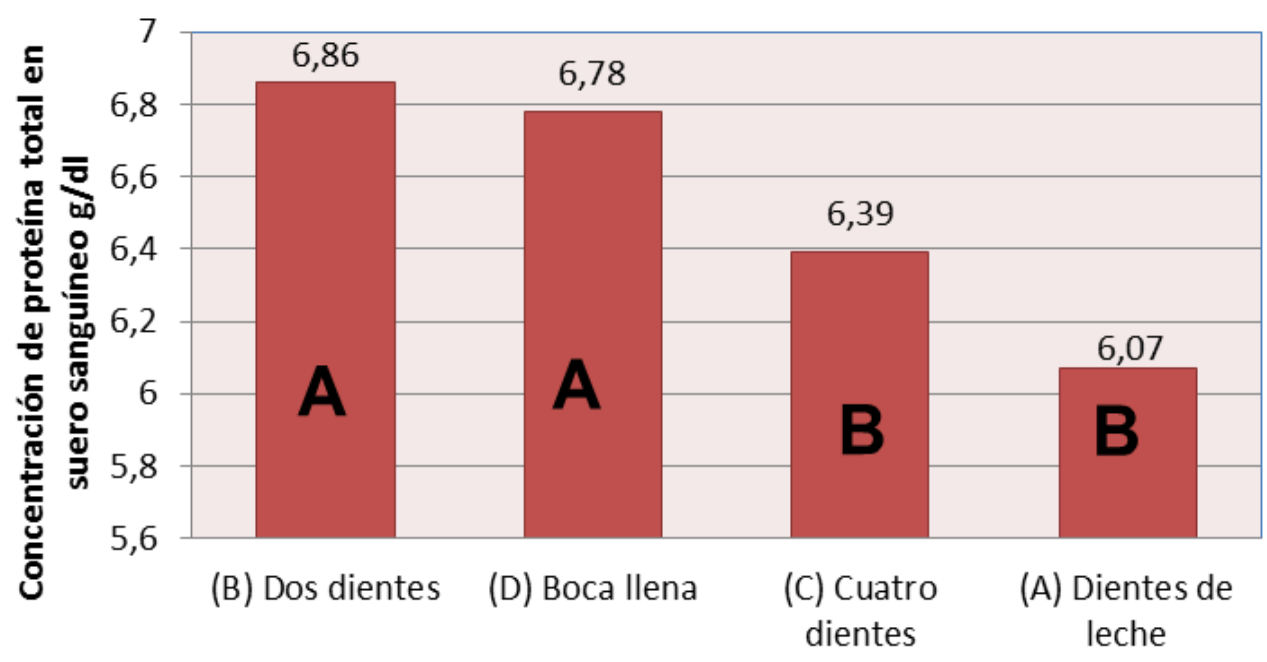

CATEGORIA DE EDAD

Gráfico 1. Comparación de medias Duncan $(\mathrm{P}<0,05)$ de los niveles séricos de proteínas totales de llamas pastoreadas en praderas nativas según categoría de edad 
El gráfico 1 de comparación de medias Duncan, muestra que la concentración de proteínas totales en suero sanguíneo de llamas pastoreadas en praderas nativas en las categorías de edad B (dos dientes) y D (boca llena) son similares estadísticamente con 6,86 $\mathrm{g} / \mathrm{dl}$ y $6,78 \mathrm{~g} / \mathrm{dl}$ respectivamente y superiores a las categorías C (cuatro dientes) y A (dientes de leche) con 6,39 g/dl y 6,07 g/dl respectivamente, estas últimas también son similares estadísticamente.

Las llamas de dos dientes y boca llena presentaron niveles séricos superiores de proteínas totales debido a que los de dos dientes son animales jóvenes con capacidad selectiva de pastos de buena calidad nutritiva (consumen los mejores pastos); y los de boca llena son animales que tienen mayor capacidad digestiva de pastos naturales (mayor capacidad para asimilar los alimentos) y mayor desarrollo de microorganismos en los compartimientos $\mathrm{C} 1$ y C2 (proteína bacteriana y de protozoarios).

Los menores niveles séricos de proteínas totales en las llamas de cuatro dientes y dientes de leche probablemente se deban a que los animales de cuatro dientes machos están en la actividad reproductiva de cruzamientos que disminuye los niveles de proteínas y las hembras se encuentran en el estado fisiológico de gestación que demanda altos niveles de utilización de proteínas para el desarrollo embrionario y fetal; mientras que las llamas dientes de leche utilizan más proteínas para el crecimiento tisular y corporal por lo que sus niveles séricos son inferiores.

En los animales cada individuo posee patrones diferentes de componentes químicos sanguíneos que pueden cambiar con la edad. Las diferencias en los niveles séricos en proteínas totales por edad están influidas por el estado fisiológico de los animales y la calidad nutritiva de los alimentos pastos nativos.

\section{Niveles séricos de albúmina de llamas pastoreadas en praderas nativas según meses, sexo y categoría de edad}

La albúmina es el responsable del $80 \%$ de la presión osmótica coloidal total que mantiene el movimiento de los líquidos del cuerpo, facilita el metabolismo y desintoxicación de diversas sustancias (bilirrubina, metales, iones, enzimas, aminoácidos, hormonas, ácidos grasos libres, fármacos y fosfolípidos) y potencia la eliminación de los radicales libres del plasma. El hígado es la principal fuente de síntesis de albúmina, si las células hepáticas están dañadas la albúmina en el suero disminuirá.

La media general de los niveles séricos de albúmina obtenidos en la investigación fue de $3,75 \pm 1,22 \mathrm{~g} / \mathrm{dl}$ con extremos de 2,53 a 4,97 $\mathrm{g} / \mathrm{dl}$ en llamas pastoreadas en praderas nativas en la comunidad Jilahuta Manasaya de Curahuara de Carangas según meses, sexo y categoría de edad. (Tabla 3) 
Tabla 3. Niveles séricos de albúmina de llamas pastoreadas en praderas nativas

\begin{tabular}{|c|c|c|c|c|c|c|}
\hline Meses & Sexo & $\begin{array}{c}\text { Categoría de } \\
\text { edad }\end{array}$ & $\mathbf{n}$ & Media $\pm 2 S D(g / d l)$ & $\begin{array}{c}\text { Min } \\
\text { (g/dl) }\end{array}$ & $\begin{array}{c}\text { Max } \\
(\mathrm{g} / \mathrm{d})\end{array}$ \\
\hline \multirow{6}{*}{ Noviembre } & \multirow{3}{*}{ Hembra } & $\mathrm{A}$ & 10 & $4,29 \pm 0,68$ & 3,60 & 4,80 \\
\hline & & B & 19 & $4,10 \pm 0,44$ & 3,80 & 4,50 \\
\hline & & $\mathrm{C}$ & 10 & $4,03 \pm 0,66$ & 3,50 & 4,40 \\
\hline & \multirow{4}{*}{ Macho } & $\mathrm{D}$ & 20 & $3,73 \pm 0,66$ & 3,20 & 4,30 \\
\hline & & A & 10 & $3,96 \pm 0,80$ & 3,40 & 4,50 \\
\hline & & $\mathrm{C}$ & 8 & $3,60 \pm 1,12$ & 2,70 & 4,10 \\
\hline \multirow{6}{*}{ Enero } & & A & 9 & $4,20 \pm 0,56$ & 3,70 & 4,60 \\
\hline & \multirow{3}{*}{ Hembra } & B & 20 & $3,84 \pm 1,06$ & 2,90 & 4,50 \\
\hline & & $\mathrm{C}$ & 9 & $4,07 \pm 0,60$ & 3,40 & 4,50 \\
\hline & & $\mathrm{D}$ & 18 & $3,86 \pm 0,66$ & 3,20 & 4,40 \\
\hline & \multirow{2}{*}{ Macho } & A & 8 & $4,10 \pm 0,64$ & 3,60 & 4,60 \\
\hline & & $\mathrm{C}$ & 8 & $3,73 \pm 0,60$ & 3,30 & 4,30 \\
\hline \multirow{6}{*}{ Marzo } & \multirow{4}{*}{ Hembra } & A & 9 & $3,81 \pm 0,38$ & 3,40 & 4,10 \\
\hline & & B & 20 & $3,47 \pm 1,56$ & 1,30 & 4,90 \\
\hline & & $\mathrm{C}$ & 10 & $3,49 \pm 1,82$ & 1,80 & 4,50 \\
\hline & & $\mathrm{D}$ & 21 & $3.24 \pm 1,14$ & 2,10 & 4,20 \\
\hline & \multirow{2}{*}{ Macho } & A & 9 & $3,05 \pm 2,38$ & 0,60 & 3,90 \\
\hline & & $\mathrm{C}$ & 7 & $3,21 \pm 1,62$ & 2,10 & 4 \\
\hline
\end{tabular}

Tabla 4. Análisis de varianza de los niveles séricos de albúmina de llamas pastoreadas en praderas nativas según meses, sexo y categoría de edad.

\begin{tabular}{lrrrrr}
\hline \multicolumn{1}{c}{ Fuente de variación } & GL & \multicolumn{1}{c}{ SC } & CM & \multicolumn{1}{c}{ FV } & Pr $>$ F \\
\hline Meses & 2 & 14,13251 & 7,06625 & 24,21 & $0,0001^{* *}$ \\
Sexo & 1 & 3,65543 & 3,65543 & 12,53 & $0,0005^{* *}$ \\
Meses x Sexo & 2 & 0,37336 & 0,18668 & 0,64 & $0,5285 \mathrm{NS}$ \\
Categoría de edad & 3 & 5,03246 & 1,67748 & 5,75 & $0,0009^{* *}$ \\
Mes x Categoría de edad & 6 & 1,04232 & 0,17372 & 0,60 & $0,7339 \mathrm{NS}$ \\
Sexo x Categoría de edad & 1 & 0,01429 & 0,01429 & 0,05 & $0,8250 \mathrm{NS}$ \\
Mes x Sexo x Categoría de edad & 2 & 0,62836 & 0,31418 & 1,08 & $0,3427 \mathrm{NS}$ \\
Error & 207 & 60,40984 & 0,29183 & & \\
Total & 224 & 85,17760 & & & \\
\hline C. & & & & & \\
\hline
\end{tabular}

C. V. $14,39 \%$ 
Según el análisis de varianza de la concentración de albúmina en suero sanguíneo, los resultados muestran que los factores meses, sexo y categoría de edad afectan de manera significativa $(\mathrm{P}<0,01)$ sobre los niveles séricos de esta proteína. El coeficiente de varianza es de 14,39\% indica que los datos obtenidos son confiables. (Tabla 4).

En este estudio se rechaza la Ho para todos los factores meses, sexo y categoría de edad por presentar resultados estadísticamente diferentes.

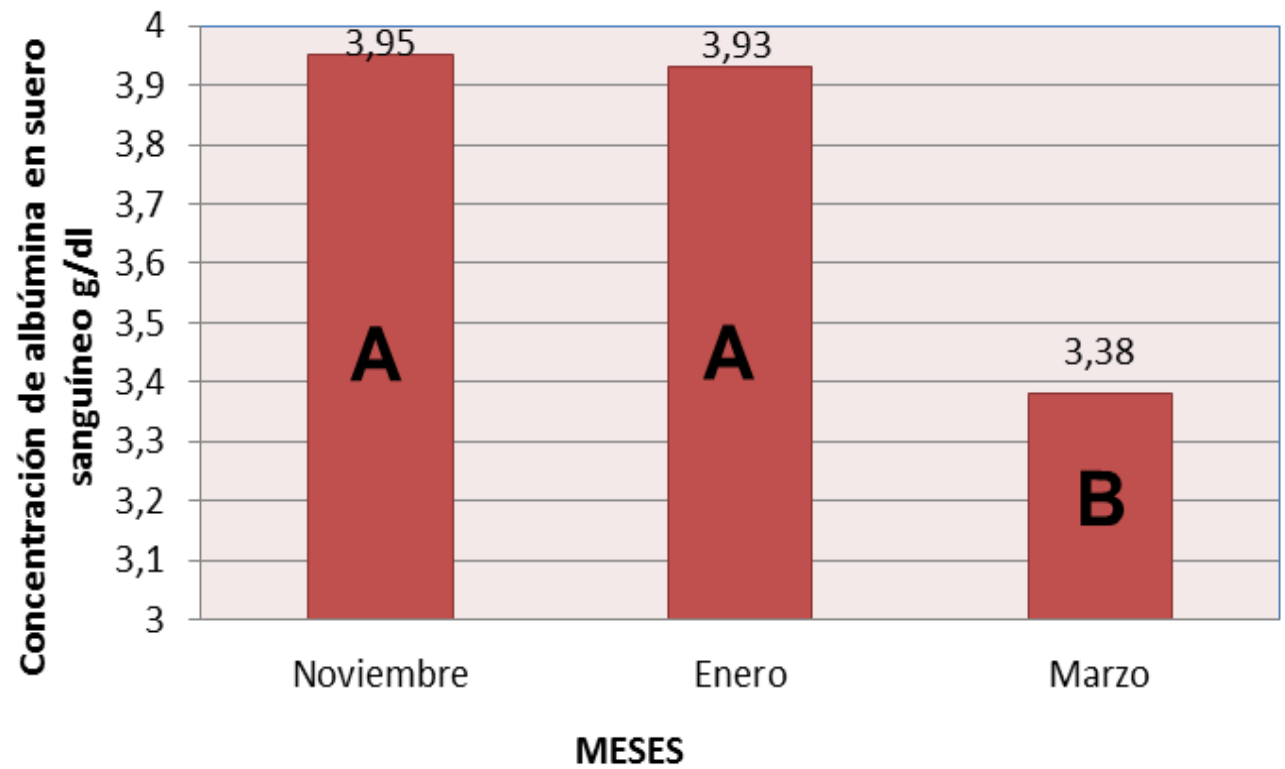

Gráfico 2. Comparación de medias Duncan $(\mathrm{P}<0,05)$ de los niveles séricos de albúmina de llamas pastoreadas en praderas nativas según meses.

El gráfico 2 de comparación de medias Duncan, muestra que los resultados de las concentraciones de albúmina en suero sanguíneo de llamas pastoreadas en praderas nativas estadísticamente son similares en los meses de noviembre y enero con 3,95 g/dl y $3,93 \mathrm{~g} / \mathrm{dl}$ respectivamente y superiores al mes de marzo que presento $3,38 \mathrm{~g} / \mathrm{dl}$.

Los niveles séricos de albúmina de los meses noviembre y enero se consideran normales por encontrarse dentro de los parámetros referenciales; mientras que durante el mes de marzo las albúminas séricas han disminuido probablemente a que las llamas hembras se encuentran en etapa de lactación que requiere mayor utilización de proteína para la producción de leche con la consecuente menor concentración de albúmina. En el caso de llamas machos la disminución posiblemente se deba a la actividad reproductiva que desempeña durante el mes de marzo.

En etapas de elevado gasto energético como la lactancia, los bajos aportes alimenticios requieren la utilización de las reservas corporales formadas en épocas de excedentes alimenticios, a fin de minimizar los efectos adversos ocasionados por el desbalance nutricional sobre las variables productivas: producción de leche, crecimiento de las crías. 
Los resultados obtenidos en la investigación son similares a los reportados por Murray (1998) de 2,9 g/dl a $5 \mathrm{~g} / \mathrm{dl}$, Ajata (2006) de 3,86 g/dl a 5,46 g/dl, Coaquira (2005) de 4,37 g/dl a $4,69 \mathrm{~g} / \mathrm{dl}$, (en llamas machos alimentados con heno de cebada, alfalfa y kiri de quinua), Choque (2009) de 3,0 g/dl a 3,4 g/dl.

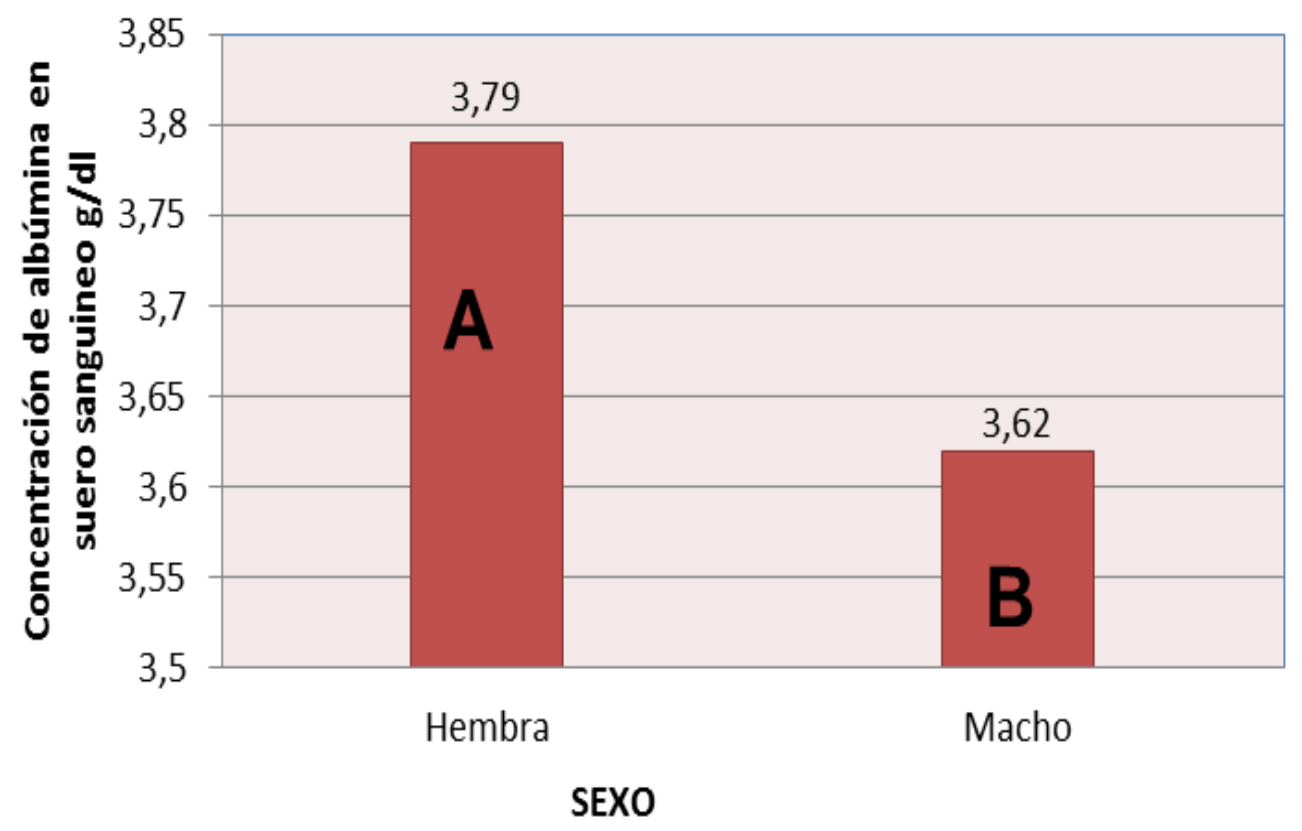

Gráfico 3. Comparación de medias Duncan $(\mathrm{P}<0,05)$ de los niveles séricos de albúmina de llamas pastoreadas en praderas nativas según sexo

Según el gráfico 3 de comparación de medias Duncan, los resultados de la concentración de albúmina en suero sanguíneo de llamas pastoreadas en praderas nativas, estadísticamente en llamas hembras fue superior con $3,79 \mathrm{~g} / \mathrm{dl}$ en relación al de los machos que presentaron $3,62 \mathrm{~g} / \mathrm{dl}$.

Los niveles de albúminas en las llamas hembras se encuentran dentro de los parámetros referenciales, indicador del normal estado fisiológico de estos animales; sin embargo la ligera disminución de los niveles séricos de albúmina en los machos obedece a la actividad sexual y a la producción de semen frecuente durante los meses en las que realizo la investigación.

Las concentraciones de albúmina sérica en vicuñas silvestres en las hembras presentan valores superiores en comparación con los machos (Garnica et al., 2003). Los resultados de la albúmina sérica están entre los rangos obtenidos por Garnica et al., (2003) de $4,20 \mathrm{~g} / \mathrm{dl}$ y $3,90 \mathrm{~g} / \mathrm{dl}$ en la vicuña hembra y macho respectivamente. 


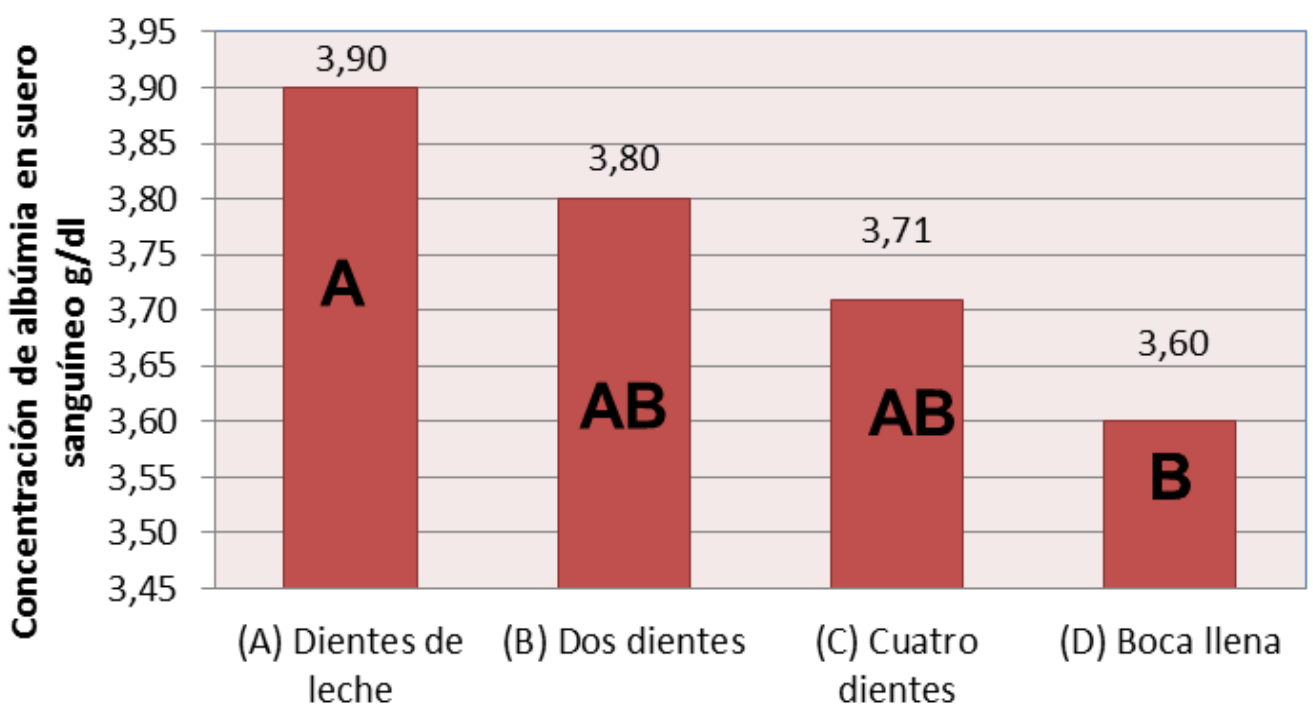

CATEGORIA DE EDAD

Gráfico 4. Comparación de medias Duncan $(\mathrm{P}<0,05)$ de los niveles séricos de albúmina de llamas pastoreadas en praderas nativas según categoría de edad.

Según el gráfico 4 de comparación de medias Duncan, la concentración de albúmina en suero sanguíneo de llamas pastoreadas en praderas nativas, fue superior en la categoría de edad A (dientes de leche) con $3,90 \mathrm{~g} / \mathrm{dl}$, respecto a la categoría de edad $\mathrm{D}$ (boca llena) que resulto ser inferior a todas las edades con $3,60 \mathrm{~g} / \mathrm{dl}$; sin embargo las categorías de edad $\mathrm{B}$ (dos dientes) y $\mathrm{C}$ (cuatro dientes) fueron similares a las categorías A y D con 3,80 g/dl y $3,71 \mathrm{~g} / \mathrm{dl}$ respectivamente.

Los animales de la categoría de edad A se caracterizan por la intensa actividad metabólica debido al crecimiento corporal por lo que los niveles de albúmina séricas son superiores para el transporte de diferentes compuestos necesarios para el desarrollo del animal. En llamas adultas de la categoría D las funciones vitales tienden a disminuir que influye a que las concentraciones séricas de albúmina disminuyan.

Las concentraciones de albúmina disminuyen a medida que aumenta la edad.
(Radostits et al., 2002). Las concentraciones séricas de albúminas en las llamas están influidas por el estado fisiológico de los animales, el clima, la calidad y cantidad de los pastos nativos.

\section{Niveles séricos de globulina de llamas pastoreadas en praderas nativas según meses, sexo y categoría de edad}

Las globulinas son los constituyentes fundamentales de los anticuerpos, su papel en el mantenimiento de la presión osmótica es mucho menor que el de la albúmina pueden actuar como proteínas transportadoras que vinculan sustancias especificas (Studdert, 1994).

La media general de los niveles séricos de globulina obtenidos fue de 2,78 $\pm 2,73 \mathrm{~g} / \mathrm{dl}$ con extremos de 0,05 a $5,51 \mathrm{~g} / \mathrm{dl}$ en llamas pastoreadas en praderas nativas en la comunidad Jilahuta Manasaya de Curahuara de Carangas según meses, sexo y categoría de edad. (Tabla 5). 
Tabla 5. Niveles séricos de globulina de llamas pastoreadas en praderas nativas

\begin{tabular}{|c|c|c|c|c|c|c|}
\hline Meses & Sexo & $\begin{array}{c}\text { Categoría de } \\
\text { edad }\end{array}$ & $\mathbf{n}$ & Media $\pm 2 S D(g / d l)$ & $\begin{array}{l}\text { Min } \\
\text { (g/dl) }\end{array}$ & $\begin{array}{l}\text { Max } \\
\text { (g/dl) }\end{array}$ \\
\hline \multirow{6}{*}{ Noviembre } & \multirow{4}{*}{ Hembra } & A & 10 & $1,36 \pm 0,72$ & 0,70 & 1,90 \\
\hline & & $\mathrm{B}$ & 18 & $2,11 \pm 1,42$ & 0,70 & 3,40 \\
\hline & & $\mathrm{C}$ & 10 & $1,98 \pm 1,30$ & 0,70 & 3 \\
\hline & & $\mathrm{D}$ & 20 & $2,43 \pm 1,50$ & 1,30 & 3,90 \\
\hline & \multirow{3}{*}{ Macho } & A & 10 & $1,69 \pm 1,50$ & 0,50 & 2,90 \\
\hline & & $\mathrm{C}$ & 8 & $2,08 \pm 1,60$ & 1,30 & 3,90 \\
\hline \multirow{6}{*}{ Enero } & & A & 9 & $1,78 \pm 1,34$ & 0,50 & 2,60 \\
\hline & \multirow{3}{*}{ Hembra } & $\mathrm{B}$ & 20 & $3,13 \pm 2,06$ & 1,30 & 6,90 \\
\hline & & $\mathrm{C}$ & 9 & $2,06 \pm 2,04$ & 0,20 & 3,70 \\
\hline & & $\mathrm{D}$ & 18 & $2,82 \pm 1,14$ & 1,90 & 4 \\
\hline & \multirow{2}{*}{ Macho } & A & 8 & $2 \pm 0,50$ & 1,80 & 2,40 \\
\hline & & $\mathrm{C}$ & 8 & $2,08 \pm 1,60$ & 1,20 & 4,10 \\
\hline \multirow{6}{*}{ Marzo } & \multirow{4}{*}{ Hembra } & $\mathrm{A}$ & 9 & $2,46 \pm 0,66$ & 2,10 & 3,20 \\
\hline & & $\mathrm{B}$ & 20 & $3,88 \pm 3,36$ & 2 & 9,20 \\
\hline & & $\mathrm{C}$ & 10 & $3,26 \pm 1,66$ & 2,40 & 5,30 \\
\hline & & $\mathrm{D}$ & 21 & $4,20 \pm 2,82$ & 0,50 & 7,10 \\
\hline & \multirow{2}{*}{ Macho } & A & 9 & $3,84 \pm 4,68$ & 1,20 & 7,70 \\
\hline & & $\mathrm{C}$ & 7 & $4,38 \pm 3,10$ & 2,70 & 6,70 \\
\hline
\end{tabular}

Tabla 6. Análisis de varianza de los niveles séricos de globulina de llamas pastoreadas en praderas nativas según meses, sexo y categoría de edad

\begin{tabular}{lrrrrc}
\hline \multicolumn{1}{c}{ Fuente de Variación } & GL & \multicolumn{1}{c}{ S C } & C M & \multicolumn{1}{c}{ F V } & Pr > F \\
\hline Meses & 2 & 8,84781 & 4,42390 & 48,13 & $0,0001^{* *}$ \\
Sexo & 1 & 0,81263 & 0,81263 & 8,84 & $0,0033^{* *}$ \\
Meses x Sexo & 2 & 0,22074 & 0,11037 & 1,20 & $0,3030 \mathrm{NS}$ \\
Categoría de edad & 3 & 4,07475 & 1,35825 & 14,78 & $0,0001^{* *}$ \\
Mes x Categoría de edad & 6 & 0,37662 & 0,06277 & 0,68 & $0,6636 \mathrm{NS}$ \\
Sexo x Categoría de edad & 1 & 0,000003 & 0,000003 & 0,00 & $0,9950 \mathrm{NS}$ \\
Mes x Sexo x Categoría de edad & 2 & 0,04264 & 0,02132 & 0,23 & $0,7932 \mathrm{NS}$ \\
Error & 206 & 18,93351 & 0,09191 & & \\
Total & $\mathbf{2 2 3}$ & $\mathbf{3 3 , 6 2 6 0 5}$ & & & \\
\hline
\end{tabular}

C. V. $10.86 \%$

5. Niveles 
El análisis de varianza (Tabla 6), muestra que los factores meses, sexo y categoría de edad influyen significativamente $(\mathrm{P}<0,01)$ sobre la concentración sérica de globulina en llamas pastoreadas en praderas nativas. El coeficiente de variación de 10,86\%, indica que los datos obtenidos son confiables.
En esta investigación se rechaza la Ho para los factores meses, sexo y categoría de edad por presentar resultados estadísticamente diferentes.

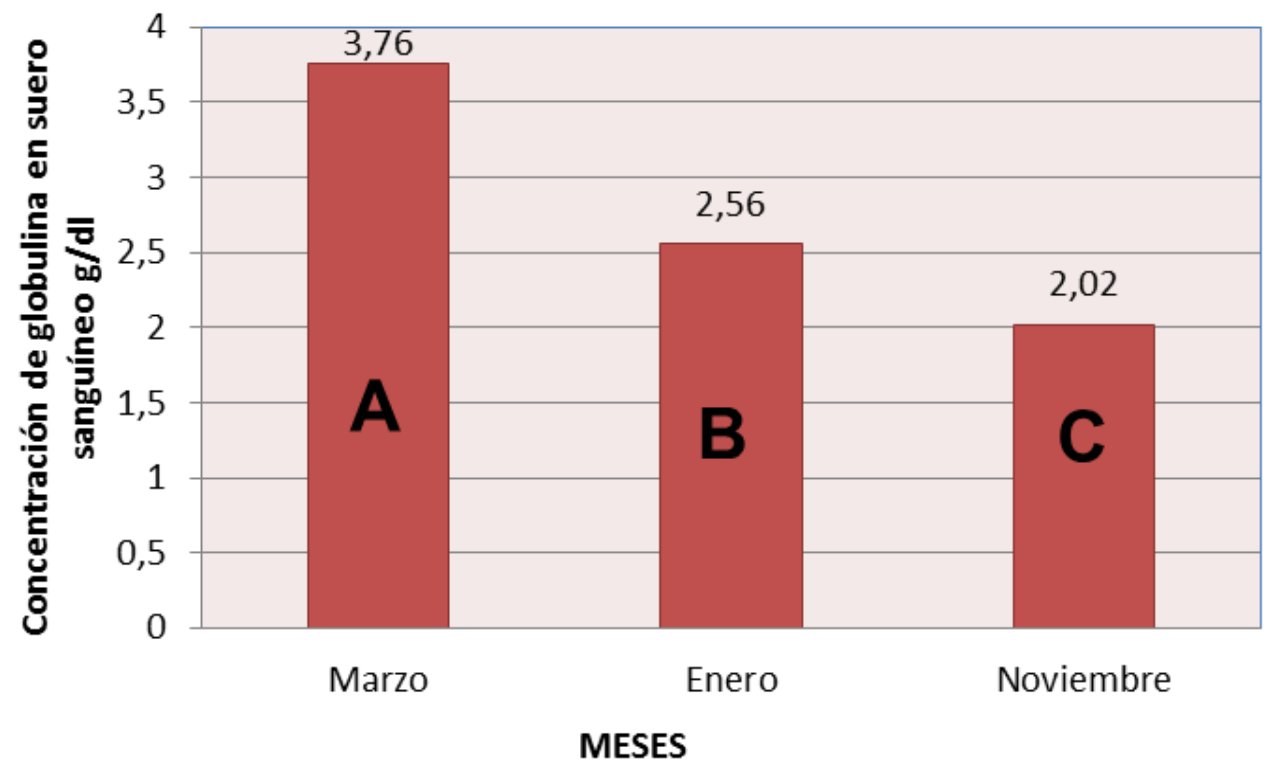

Gráfico 5. Comparación de medias Duncan $(\mathrm{P}<0,05)$ de los niveles séricos de globulina de llamas pastoreadas en praderas nativas según meses

El gráfico 5 de comparación de medias Duncan, muestra que la concentración de globulina en suero sanguíneo de las llamas pastoreadas en praderas nativas según meses, es superior en el mes de marzo de 3,76 g/dl, seguido por los niveles séricos del mes de enero con 2,56 g/dl; mientras que los niveles de globulina en el mes de noviembre es inferior a las anteriores.

Los niveles séricos de globulina de los meses de noviembre y enero se consideran normales por encontrarse dentro de los rangos referenciales; mientras que durante el mes de marzo los pastos nativos se encuentran en estado fenológico de floración que se caracteriza por su alto contenido nutritivo y fibra digerible que influye a que los microorganismos de los compartimientos (C1) y los compartimientos (C2) proliferan con la consecuente madurez los niveles séricos de las globulinas sean altos en llamas.

La globulina sérica forma parte de metabolismo convencional, sus concentraciones sanguíneas están reguladas por el balance entre el aporte de la dieta, brindan información rápida y precisa del metabolismo animal. Los resultados obtenidos en La presente investigación indican que existe buen aporte de proteína en la dieta durante el mes de marzo con el consecuente nivel alto de globulina sérica. 
Los resultados obtenidos son similares a los a los de Coaquira (2005), de 1,48 g/dl a $1,96 \mathrm{~g} / \mathrm{dl}$, Murray (1998) de 1,4 g/dl a 3,3 $\mathrm{g} / \mathrm{dl}$.

Las diferencias en los niveles séricos de globulinas en las llamas están influidas por el estado fenológico de los pastos que son parte de la dieta de las llamas, las mismas que están relacionadas con las características climáticas particulares que se presentan en los diferentes meses del año.

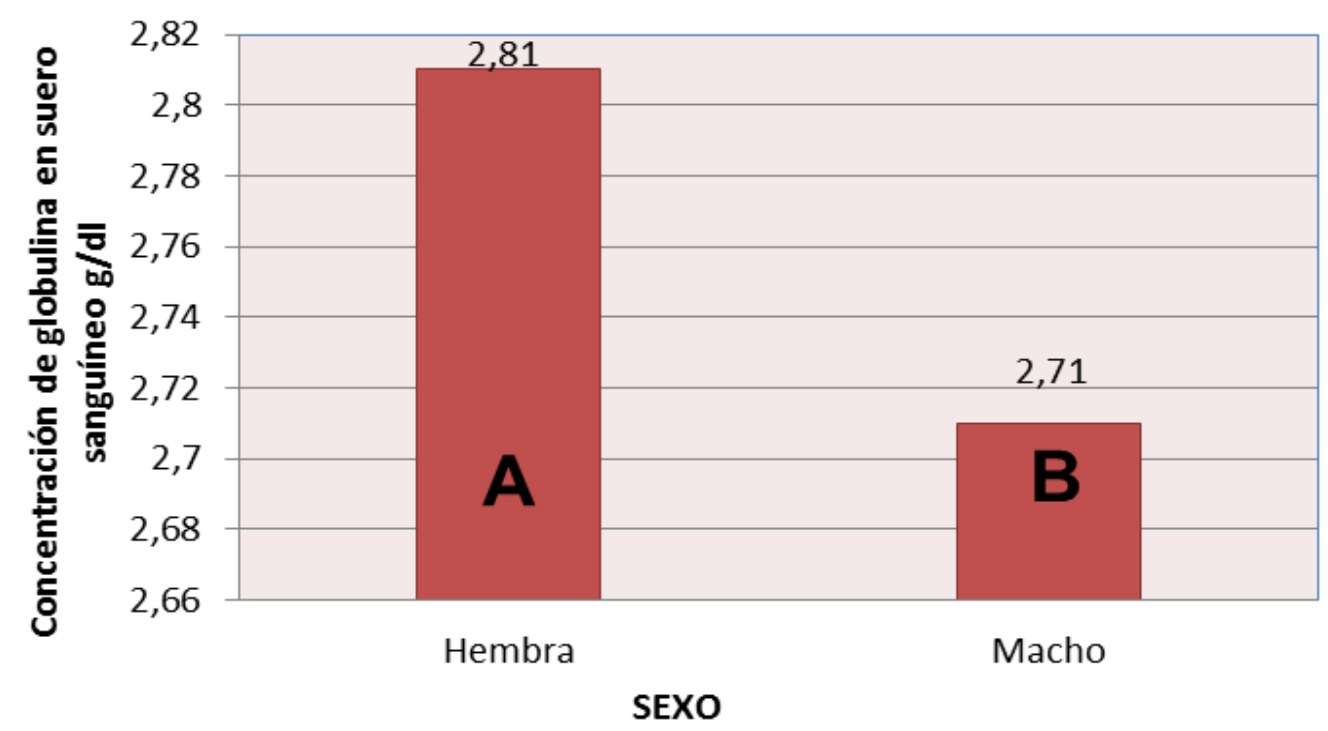

Gráfico 6. Comparación de medias Duncan $(\mathrm{P}<0,05)$ de los niveles séricos de globulina de llamas pastoreadas en praderas nativas según sexo.

Según el gráfico 6 de comparación de medias Duncan, los resultados de la concentracion de globulina en suero sanguineo de llamas patoreadas en praderas nativas, estadísticamente en llamas hembras fue superior con $2,81 \mathrm{~g} / \mathrm{dl}$ en comparación al de los machos de $2,71 \mathrm{~g} / \mathrm{dl}$.

Las concentraciones de globulina sérica en llamas hembras y machos están dentro de los parámetros referenciales; sin embargo la mayor parte de las llamas hembras se encuentran en el último tercio de gestación y otras en la etapa post parto por la que las concentraciones séricas de globulina mantienen a pesar de la producción de calostro y el inicio de la etapa de lactancia.

Para determinar la causa de la elevación de las globulinas es necesaria la separación, de cada una de sus fracciones. Cada fracción separada permitiría una interpretación más eficiente de los valores obtenidos (Jones, 2001). 


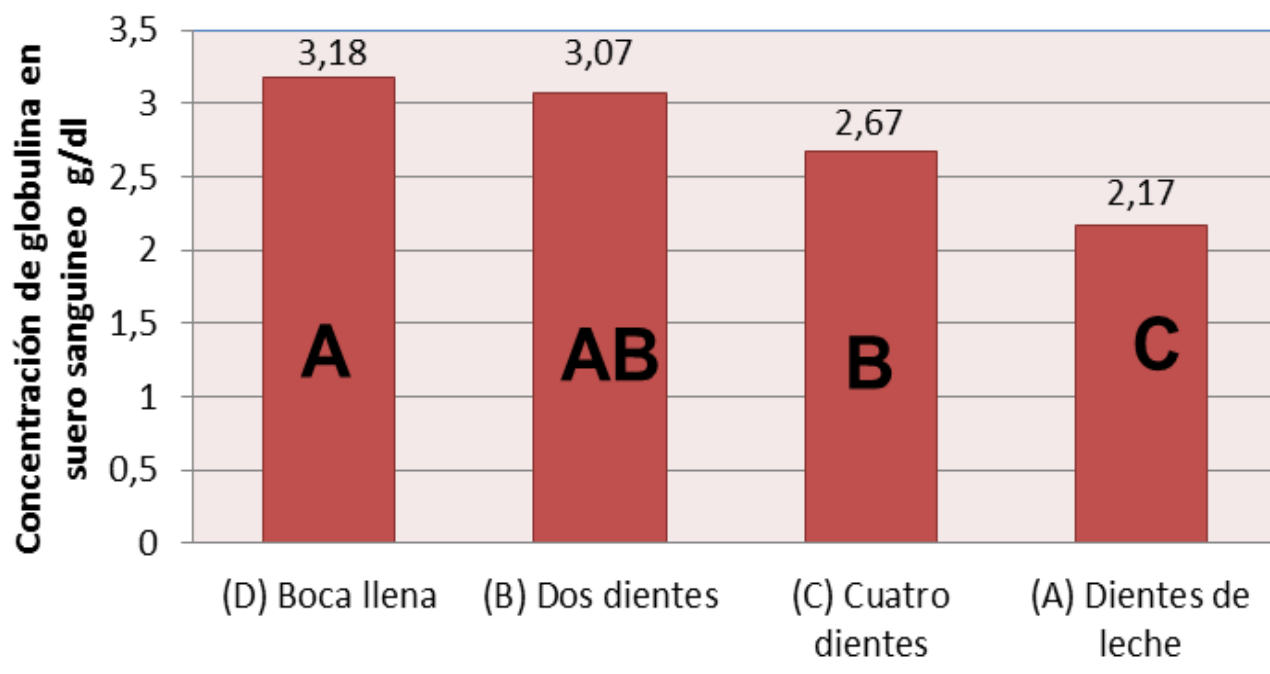

CATEGORIA DE EDAD

Gráfico 7. Comparación de medias Duncan $(\mathrm{P}<0,05)$ de los niveles séricos de globulina de llamas pastoreadas en praderas nativas según categoría de edad

Según el gráfico 7 de comparación de medias Duncan, muestran que la concentración de globulinas en suero sanguíneo de llamas pastoreadas en praderas nativas en las categorías de edad D (boca llena) y B (dos dientes) son similares estadísticamente con $3,18 \mathrm{~g} / \mathrm{dl}, 3,07 \mathrm{~g} / \mathrm{dl}$ respectivamente; la categoría de edad $\mathrm{C}$ (cuatro dientes) con 2,67 g/dl es inferior a la categoría D y similar a la categoría $\mathrm{B}$ y la categoría A (dientes de leche) con 2,17 g/dl es inferior a las anteriores categorías.

Las llamas de boca llena y dos dientes presentaron niveles séricos superiores de globulina debido a que los de dos dientes son animales jóvenes con capacidad selectiva de pastos de buena calidad nutritiva; y los de boca llena son animales que tienen mayor capacidad digestiva.

Los menores niveles séricos de globulina en las llamas de cuatro dientes y dientes de leche, probablemente se deban a que los animales de cuatro dientes machos están en la actividad reproductiva de cruzamientos y las hembras se encuentran en el estado fisiológico de gestación (desarrollo embrionario y fetal) factores que disminuyen los niveles de globulina. Las llamas dientes de leche utilizan las concentraciones de globulina para el crecimiento tisular $\mathrm{y}$ corporal por lo que sus niveles séricos son inferiores.

En los animales cada individuo posee patrones diferentes de componentes químicos sanguíneos que pueden cambiar con la edad. Las diferencias en los niveles séricos en globulinas por edad están influidas por el estado fisiológico de los animales y la calidad nutritiva de los alimentos pastos nativos.

\section{Niveles séricos de urea de llamas pastoreadas en praderas nativas según meses, sexo y categoría de edad}

Las proteínas de la dieta, en los compartimientos (C1) y el compartimiento (C2) de las llamas, son utilizadas y degradadas por los microorganismos en aminoácidos y una parte importante 
convertidas en urea, amonio y proteínas microbianas. El hígado de las llamas cumple un papel clave en el metabolismo y formación de la urea a partir del amonio absorbido por las paredes de los compartimientos (C1) y (C2) y aminoácidos y péptidos absorbidos a nivel duodenal.
La media general de los niveles séricos de urea obtenidos fue de $36,94 \pm 25,24 \mathrm{mg} / \mathrm{dl}$ con extremos de 11,70 a $62,18 \mathrm{mg} / \mathrm{dl}$ en llamas pastoreadas en praderas nativas en la comunidad Jilahuta Manasaya de Curahuara de Carangas según meses, sexo y categoría de edad. (Tabla 6).

Tabla 6. Niveles séricos de urea de llamas pastoreadas en praderas nativas

\begin{tabular}{|c|c|c|c|c|c|c|}
\hline Meses & Sexo & $\begin{array}{c}\text { Categoría } \\
\text { de edad }\end{array}$ & $\mathbf{n}$ & $\begin{array}{c}\text { Media } \pm 2 \text { DS } \\
(\mathrm{mg} / \mathrm{dl})\end{array}$ & $\begin{array}{l}\text { Min } \\
\text { (mg/dl) }\end{array}$ & $\begin{array}{l}\text { Max } \\
\text { (mg/dl) }\end{array}$ \\
\hline \multirow{6}{*}{ Noviembre } & \multirow{4}{*}{ Hembra } & A & 10 & $38,19 \pm 18$ & 18,50 & 50,20 \\
\hline & & B & 19 & $33,86 \pm 18$ & 18,50 & 49,60 \\
\hline & & $\mathrm{C}$ & 10 & $37 \pm 26$ & 11,70 & 52,60 \\
\hline & & $\mathrm{D}$ & 20 & $31,26 \pm 26$ & 14,50 & 64,40 \\
\hline & \multirow{3}{*}{ Macho } & A & 10 & $45,48 \pm 26$ & 15,80 & 62,50 \\
\hline & & $\mathrm{C}$ & 8 & $31,63 \pm 17$ & 19,60 & 47,70 \\
\hline \multirow{6}{*}{ Enero } & & A & 8 & $40,70 \pm 20$ & 31,10 & 56,20 \\
\hline & \multirow{3}{*}{ Hembra } & B & 20 & $41,37 \pm 19$ & 24,30 & 55,40 \\
\hline & & C & 9 & $46,58 \pm 23$ & 29,50 & 58,60 \\
\hline & & D & 19 & $46,68 \pm 27$ & 22,10 & 69,50 \\
\hline & \multirow{2}{*}{ Macho } & A & 8 & $34,98 \pm 37$ & 12 & 67,10 \\
\hline & & $\mathrm{C}$ & 8 & $32,11 \pm 17$ & 20,20 & 44,20 \\
\hline \multirow{6}{*}{ Marzo } & \multirow{4}{*}{ Hembra } & A & 8 & $39,75 \pm 17$ & 27,72 & 59,17 \\
\hline & & B & 20 & $29,26 \pm 21$ & 12,13 & 45,92 \\
\hline & & $\mathrm{C}$ & 10 & $40,29 \pm 18$ & 28,76 & 51,17 \\
\hline & & D & 20 & $38,33 \pm 24$ & 21,63 & 58,76 \\
\hline & \multirow{2}{*}{ Macho } & A & 9 & $31,28 \pm 23$ & 18,41 & 48,47 \\
\hline & & $\mathrm{C}$ & 7 & $22,70 \pm 27$ & 6,92 & 39,46 \\
\hline
\end{tabular}


Tabla 7. Análisis de varianza de los niveles séricos de urea de llamas pastoreadas en praderas nativas según meses, sexo y categoría de edad.

\begin{tabular}{lrrrrl}
\hline \multicolumn{1}{c}{ Fuente de Variación } & GL & \multicolumn{1}{c}{ S C } & \multicolumn{1}{c}{ C M } & F V & Pr > F \\
\hline Meses & 2 & 12,44365 & 6,22182 & 6,47 & $0,0019^{* *}$ \\
Sexo & 1 & 12,35168 & 12,35168 & 12,85 & $0,0004^{* *}$ \\
Meses x Sexo & 2 & 8,31241 & 4,15620 & 4,32 & $0,0145^{*}$ \\
Categoría de edad & 3 & 8,69678 & 2,89892 & 3,02 & $0,0310^{*}$ \\
Mes x Categoría de edad & 6 & 10,99731 & 1,83288 & 1,91 & 0,0812 NS \\
Sexo x Categoría de edad & 1 & 4,28894 & 4,28894 & 4,46 & $0,0359 *$ \\
Mes x Sexo x Categoría de edad & 2 & 0,23718 & 0,11859 & 0,12 & $0,884 \mathrm{NS}$ \\
Error & 205 & 197,06021 & 0,96126 & & \\
\hline Total & $\mathbf{2 2 2}$ & $\mathbf{2 5 9 , 0 0 3 8 2}$ & & & \\
\hline C & & & & &
\end{tabular}

C.V. $2,65 \%$

En el tabla 7 el análisis de varianza se observó para los factores meses y sexo la diferencia significativa $(\mathrm{P}<0,01)$, para el factor categoría de edad y las interacciones meses por sexo, sexo por categoría de edad $(\mathrm{P}<0,05)$, afectan significativamente sobre los niveles séricos de urea en llamas pastoreadas en praderas nativas.
Los resultados estadísticamente diferentes rechaza la Ho para los factores meses, sexo y categoría de edad. El coeficiente de variación de 2,65\% indica que los datos obtenidos durante la investigación son confiables.

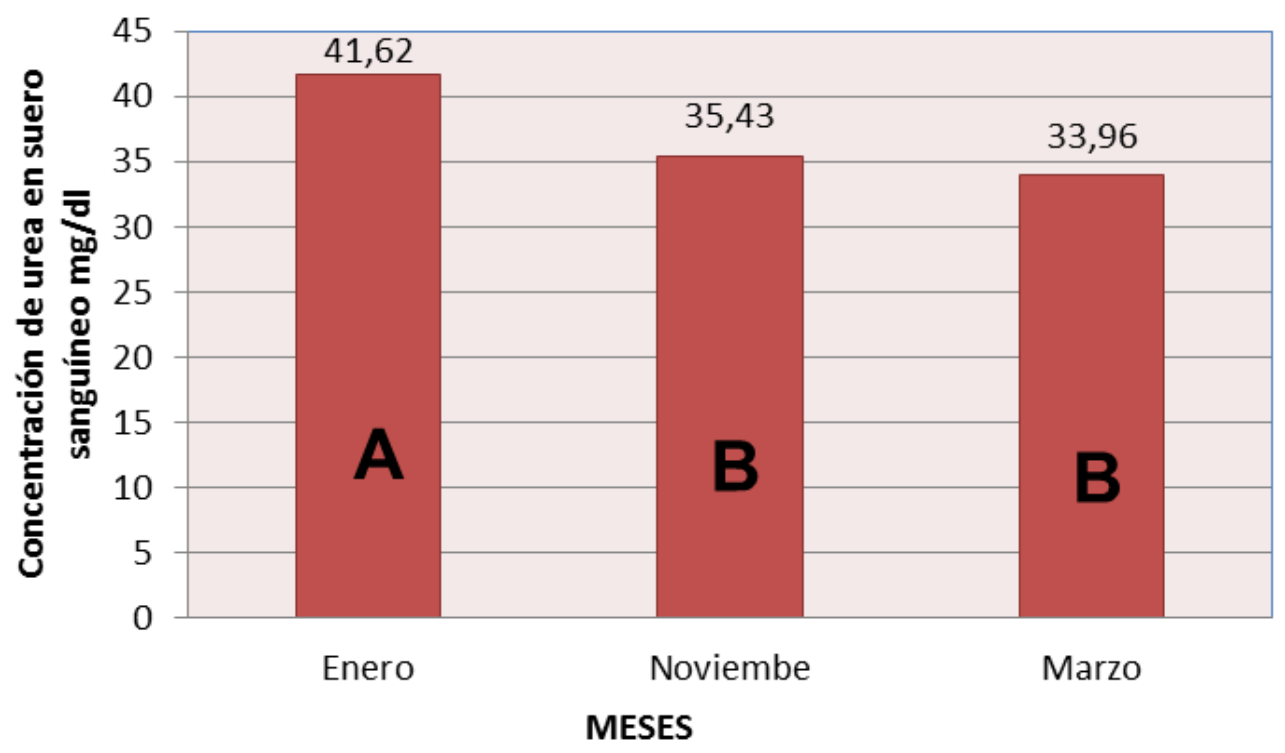

Gráfico 8. Comparación de medias Duncan $(\mathrm{P}<0,05)$ de los niveles séricos de urea de llamas pastoreadas en praderas nativas según meses. 
El gráfico 8 de comparación de medias Duncan, muestra que la concentración de urea en suero sanguíneo de llamas pastoreadas en praderas nativas según meses, es superior en el mes de enero con $41,62 \mathrm{mg} / \mathrm{dl}$; mientras que los niveles de urea en los meses de noviembre con 35,43 $\mathrm{mg} / \mathrm{dl}$ y marzo con $33,96 \mathrm{mg} / \mathrm{dl}$ son similares estadísticamente e inferiores con respecto al mes de enero.

Durante el mes de enero las concentraciones séricas de urea fueron superiores debido a que los pastos nativos se encuentran en etapa de crecimiento (tiernos) y son muy digeribles para los microorganismos, además las llamas hembras por estar en etapa de parición y lactancia exigen mayores requerimientos proteicos que son asociados al efecto nivelador. Los pastos nativos en el mes de noviembre fueron secos y contenido de fibra no digerible y en marzo en proceso de maduración.

Hay una relación directa entre la ingesta proteica y la concentración de nitrógeno ureico en sangre. Las concentraciones bajas de urea indican que la ingesta proteica es mínima debido al estado fenológico y la calidad de los pastos, que están relacionadas con las características climáticas particulares en los diferentes meses del año.

Las llamas metabolizan la urea de manera diferente que otros rumiantes y tienen una intrínseca tasa metabólica elevada de utilización de proteína o alguna combinación de estos factores (Van Saun, 2004).

La urea se forma tanto por catabolismo de las proteínas endógenas como por degradación de las proteínas alimentarias. La privación de alimentos no influye en la concentración de nitrógeno debido probablemente a la utilización de la urea (reciclaje) como fuente de nitrógeno no proteico (NNP), y al catabolismo que sufren las proteínas como respuesta a la restricción de alimento (Quisbert, 2008).

Los resultados de la concentración sérica de urea obtenida en el presente estudio, se encuentran entre los parámetros encontrados por Quispe (2007) de $48 \mathrm{mg} / \mathrm{dl} \mathrm{a} 58 \mathrm{mg} / \mathrm{dl} \mathrm{y}$ Choque (2009) de $37,1 \mathrm{mg} / \mathrm{dl} \mathrm{a} 44,5 \mathrm{mg} / \mathrm{dl}$.

Los niveles séricos de urea son superiores en el presente estudio en comparación a los reportados por Murray (1998) de 9 a 36 mg/dl, Quisbert (2008) de $15,4 \mathrm{mg} / \mathrm{dl}$ a $25,3 \mathrm{mg} / \mathrm{dl}$, Ajata (2006) de $10,77 \mathrm{mg} / \mathrm{dl}$ a $17,57 \mathrm{mg} / \mathrm{dl}$ y Coaquira (2005) en llamas alimentadas con dieta de heno de cebada, heno de alfalfa y kiri de quinua.

\section{Niveles séricos de creatinina de llamas pastoreadas en praderas nativas según meses, sexo y categoría de edad}

La creatinina se encuentra en forma homogénea en todo el cuerpo es fuente de energía para los músculos (Zapata, 2001), es el resultado de la degradación de la creatina que es componente de los músculos, la producción de creatinina depende de la modificación de la masa muscular (Balcells, 2001).

La media general de los niveles séricos de creatinina obtenidos es de $1,66 \pm 0,92 \mathrm{mg} / \mathrm{dl}$ con extremos de 0,74 a $2,58 \mathrm{mg} / \mathrm{dl}$ en llamas pastoreadas en praderas nativas en la comunidad Jilahuta Manasaya de Curahuara de Carangas según meses, sexo y categoría de edad.

Según el análisis de varianza de la concentración de creatinina en suero sanguíneo (Cuadro 28), se observa diferencia significativa para el factor meses $(\mathrm{P}<0,01)$, factor sexo y la interacción meses por categoría de edad $(\mathrm{P}<0,05)$, afectan significativamente sobre los niveles séricos de creatinina de llamas pastoreadas en praderas nativas. El coeficiente de varianza de 11,20\%, 
indica que los datos obtenidos en la investigación son confiables.

Por los resultados estadísticamente similares se acepta la Ho para el factor categoría de edad, se rechaza para los factores meses y sexo por presentar resultados estadísticamente diferentes.

Los niveles séricos de creatinina de los meses de noviembre, enero y marzo se consideran normales por encontrarse dentro de los rangos referenciales; tomando en cuenta que las concentraciones de creatinina no son afectadas por la dieta. Las diferencias se pueden atribuir a que los animales sufrieron estrés debido a la parición, lactación $\mathrm{y}$ presencia de lluvias que ha incrementado los niveles séricos de creatinina.

A diferencia de la urea, la creatinina tiene la ventaja de ser independiente de la alimentación y que no está influida por el metabolismo proteico endógeno. Por ello no es aparentemente "normal" en casos de deficiencias alimentarias y no puede reducir con medidas dietéticas. Por ello la determinación de su concentración en suero es más segura. Puesto que esencialmente solo se filtra a nivel glomerular la creatinina fundamentalmente permite valorar la función glomerular (Kraft, 2000).

Los resultados obtenidos en el fueron similares a los reportados por Murray (1998) de 0,9 a $2,8 \mathrm{mg} / \mathrm{dl}$, Quispe (2007) de 1,3 $\mathrm{mg} / \mathrm{dl}$ a $2,3 \mathrm{mg} / \mathrm{dl}$, Ajata (2006) de 1,36 $\mathrm{mg} / \mathrm{dl}$ a $1,98 \mathrm{mg} / \mathrm{dl}$, Choque (2009) de $1,9 \mathrm{a}$ $2,2 \mathrm{mg} / \mathrm{dl}$ alimentadas con pasto natural.

Los niveles de creatinina sérica en llamas hembras y machos se encuentran dentro de los parámetros referenciales; pese a que gran parte de las llamas hembras han estado en el último tercio de gestación, parición, lactación y más la presencia de lluvias y la captura para colección de muestras.
Los niveles altos de creatinina en los primeros meses de gestación respecto a las fases del último tercio y postparto, se deben a que los animales sufren un estrés en la colección de muestra (Ticona, 2009).

La creatinina solo se encuentra en mayor cantidad en animales en crecimiento y no es modificada por el contenido de proteína en la que corresponde animales ancutas menores de dos años dientes de leche (Ticona, 2009). Los recién nacidos poseen un nivel de creatinina en sangre notablemente alto (Kraft, 2000).

\section{Niveles séricos de bilirrubina directa de llamas pastoreadas en praderas nativas según meses, sexo y categoría de edad}

La bilirrubina conjugada es excretada al duodeno por el sistema biliar (una pequeña cantidad pasa directamente al torrente circulatorio). Sin embargo, parte del urubilinógeno es reabsorbido y pasa a la sangre desde donde vuelve al hígado para ser reexcretado con la bilis y se elimina por orina a través del riñón en forma de urubilinógeno (Kraft, 1998).

La media general de los niveles séricos de bilirrubina directa obtenidos en la presente investigación fue $0,70 \pm 0,49 \mathrm{mg} / \mathrm{dl}$ con extremos de 0,21 a $1,19 \mathrm{mg} / \mathrm{dl}$ en llamas pastoreadas en praderas nativas en la comunidad Jilahuta Manasaya de Curahuara de Carangas según meses, sexo y categoría de edad.

Las concentraciones séricas de bilirrubina directa en llamas pastoreadas en praderas nativas están dentro de los parámetros referenciales; las diferencias podrían atribuirse a los factores estresantes como reproducción y la presencia de lluvias.

El esfuerzo físico excesivo, la lucha en los animales en cautividad, el temor y la 
excitación o miedo, el dolor es un factor estresante, hacinamiento con agotamiento físico asociado con la permanencia en pie, durante largos periodos de pisoteamiento, acoso causado por el hombre, uno de los más importantes aquellos animales que están acostumbradas a mantenerse en rebaños o grupos, se angustian si es separa durante un cierto tiempo (Radostits et al., 2002).

Aunque la ictericia es el resultado de la acumulación de bilirrubina, la coloración es mucho más intensa en caso de la bilirrubina conjugada (directa) que en el de la no conjugada (indirecta) (Radostits et al., 2002).

Los resultados obtenidos fueron superiores a los reportados por Murray

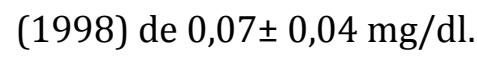

Según los resultados obtenidos, los niveles séricos de bilirrubina directa en animales jóvenes se mantienen altos, disminuyendo a medida que van creciendo. Los niveles séricos de bilirrubina directa en el mes de enero están dentro el rango reportado por Murray (1998); sin embargo, las concentraciones son relativamente superiores en el mes de noviembre y marzo.

La ictericia neonatatal es relativamente frecuente en niños pero rara vez se manifiesta clínicamente en los animales y se considera un trastorno benigno. Que puede descubrirse en la necropsia, es considerado un estado de naturaleza hemolítica, como resultado de la destrucción en exceso de eritrocitos al comenzar la vida postnatal (Radostits et al., 2002).

\section{Niveles séricos de bilirrubina total de llamas pastoreadas en praderas nativas según meses, sexo y categoría de edad}

La bilirrubina se forma a merced de la desintegración de los hematíes viejos y en la medula ósea por la degradación intracorpuscular de la hemoglobina de los eritrocitos inmaduros. En ambos procesos queda libre la hemoglobina transformándose en bilirrubina recibe los nombres de bilirrubina pre hepático, insoluble, indirecta o no conjugada (Gómez et al., 1992).

Los resultados obtenidos fueron superiores a los reportados por Murray (1998) de 0,13 $\pm 0,03 \mathrm{mg} / \mathrm{dl}$, Garnica (1985) de 0,37 mg/dl, Gómez (1992) en bovinos <0,5 $\mathrm{mg} / \mathrm{dl}$ en ovinos $0,09 \mathrm{mg} / \mathrm{dl} \mathrm{a} 0,46 \mathrm{mg} / \mathrm{dl}$, Kraft (2000) en equinos 0,5 mg/dl a 3,5 $\mathrm{mg} / \mathrm{dl}$.

Los niveles séricos de la bilirrubina en alpacas son: crías (6 meses) $0.69 \mathrm{mg} / \mathrm{dl}$, tuis (1 a 2 años) $0,49 \mathrm{mg} / \mathrm{dl}$, adultos (3 a 5 años) $0,37 \mathrm{mg} / \mathrm{dl}$, viejos (7 años) $0,14 \mathrm{mg} / \mathrm{dl}$ (Garnica et al., 2003).

Las llamas de la categoría de edad A (dientes de leche) por efecto de las interacciones categoría de edad por meses, durante la investigación presentaron resultados estadísiticamente similares en los meses de noviembre $(3,21 \mathrm{mg} / \mathrm{dl})$, enero $(3,80 \mathrm{mg} / \mathrm{dl})$ y marzo $(3,16 \mathrm{mg} / \mathrm{dl})$.

Los mayores niveles de bilirribina total obtenidas en el mes de noviembre en llamas de las categorías de edad B, C y $\quad$ D probablemente se deban al factor de estrés provocadas por la manipulación de animales durante el muestreo de sangre y el ligero incremento en marzo por la parición, lactación y el empadre.

Los niveles séricos de bilirrubina total superiores en las hembras durante el mes de noviembre se pueden atribuir al factor estrés provocados por la manipulación de los animales durante el muestreo de sangre y por el estado de gestación de una gran parte de las llamas en estudio; situación que ha disminuido en el mes de enero debido a que los animales se adaptaron al muestreo y en el mes de marzo se incrementa por la parición, lactación y empadre. 
En los machos los resultados muestran que el efecto de la manipulación no generó mucho estrés por lo que los niveles fueron constantes durante los meses de estudio.

Los niveles séricos de la bilirrubina en alpacas, no está influenciada por la raza ni el sexo (Garnica, et al., 2003).

\section{Peso vivo de llamas pastoreadas en praderas nativas según meses, sexo y categoría de edad}

En la práctica, las características del medio ambiente del animal, especialmente la nutrición, determinan el crecimiento e incluso determinar la pérdida de peso de los animales, tras lo cual, en los periodos de abundancia de los alimentos, los animales crecen rápidamente (Donald, et al., 1999).

Los resultados del peso vivo de llamas pastoreadas en praderas nativas, en las hembras fue superior debido a que el mayor número de animales entre las categorías de edad B (dos dientes) y D (boca llena) constituyeron el tamaño de muestra durante el estudio; estos animales se caracterizan por su mayor desarrollo corporal y se encuentran en el último tercio de gestación con capacidad de mayor consumo de alimentos.

Las llamas machos presentaron resultados de pesos vivos inferiores con relación a las hembras, debido a que el mayor número de estos animales que conformaron el tamaño de muestra fueron de la categoría de edad A (dientes de leche); sin embargo, los machos de la categoría de edad C (cuatro dientes) que son reproductores de la tama resultaron con pesos vivos inferiores por que se encuentran en plena actividad reproductiva (sementales) que se caracteriza en gastos elevados de energía con la consecuente pérdida de peso vivo.

En los animales adultos hay además una marcada pérdida de peso corporal, sobre todo en las situaciones de demanda elevada de energía y proteínas (Radostits et al., 2002).

Las diferencias del peso vivo en las distintas categorías de edad de llamas pastoreadas en praderas nativas, obedece al desarrollo corporal y estado fisiológico que presentan estos animales. Las llamas muy jóvenes (dientes de leche) se encuentran en pleno estado de crecimiento y tiene peso vivo inferiores con respecto a los de otras categorías de edad que han alcanzado mayor desarrollo corporal por la edad, mayor capacidad digestiva y consumo de pastos de praderas nativas.

\section{CONCLUSIONES}

Sobre la base de los objetivos planteados para la interpretación y recogida de la información en el desarrollo de la investigación, se tiene las siguientes conclusiones:

Los niveles séricos de las llamas pastoreadas en praderas nativas fueron: proteína total $6,54 \pm 2,23 \mathrm{~g} / \mathrm{dl}$, albúmina de $3,75 \pm 1,22 \mathrm{~g} / \mathrm{dl}$, globulina de $2,78 \pm 2,73 \mathrm{~g} / \mathrm{dl}$ y urea de $36,94 \pm 25,24 \mathrm{mg} / \mathrm{dl}$, los niveles séricos son influidos por los factores: meses y categoría de edad $(\mathrm{P}<0,01)$ en las proteínas totales; meses, sexo y categoría de edad $(\mathrm{P}<0,01)$ en la albúmina y globulina; meses, sexo $(\mathrm{P}<0,01)$ y categoría de edad $(\mathrm{P}<0,05)$ en la urea.

Los niveles séricos de las llamas pastoreadas en praderas nativas fueron: creatinina de 1,66 $\pm 0,92 \mathrm{mg} / \mathrm{dl}$, bilirrubina directa de $0,70 \pm 0,49$ y bilirrubina total de $3,47 \pm 2,33 \mathrm{mg} / \mathrm{dl}$ : los niveles séricos son influidos por los factores; meses $(\mathrm{P}<0,01) \mathrm{y}$ sexo $(\mathrm{P}<0,05)$ en la creatinina; meses $(\mathrm{P}<0,05)$ en la bilirrubina directa y bilirrubina total.

En las llamas cada individuo posee patrones diferentes de componentes químicos sanguíneos que pueden cambiar 
por el efecto de los meses del año, el sexo y la edad. Los niveles séricos de proteína total, albumina, globulina y urea son influidas significativamente por el clima, la calidad y cantidad de pastos y el estado fisiológico de los animales. Los microorganismos tienen un efecto nivelador sobre el aporte de proteína al animal por lo que los niveles séricos de urea en todas las categorías de edad se mantienen homogéneas.

Los niveles séricos de creatinina, bilirrubina directa y bilirrubina total no son afectados por la dieta, las diferencias obtenidas se deben a que los animales sufrieron estrés debido a la parición, lactación, empadre y presencia de lluvias que ha incrementado los niveles. Los niveles séricos de bilirrubina directa y total en animales jóvenes se mantienen altos disminuyendo a medida que van creciendo, asimismo en las épocas de pastos pobres estos niveles son relativamente altos.

El peso vivo de llamas pastoreadas en praderas nativas está influido significativamente $(\mathrm{P}<0,01)$ por los factores sexo y categoría de edad. Las diferencias del peso vivo según sexo se debe al estado fisiológico de los animales y las diferencias en las distintas categorías de edad son el resultado del desarrollo corporal y estado fisiológico que presentan estos animales. La media general del peso vivo de llamas fue $67,54 \mathrm{~kg}$.

\section{REFERENCIAS}

Ajata A., M. (2006). Perfil metabólico de balance de nitrógeno en llamas (Lama glama) alimentadas con jipi de quinua y heno de cebada, municipio de Viachadepartamento de La Paz. Tesis de grado. Universidad católica Boliviana "San Pablo". Carrera Ingeniería Zootécnica. La Paz-Bolivia

Quisbert E., AE. (2008). Efecto de la Privación de Alimentos en el Perfil Metabólico de Llamas (Lama glama) En La Estación Experimental de Letanias- Viacha. Tesis de grado. Universidad Mayor de San Andrés. Carrera Ingeniería Agronómica. La PazBolivia

Balcells, A. (2001). La Clínica en el laboratorio. Interpretación de análisis y pruebas funcionales, exploración de los síndromes, cuadro biológico de las enfermedades. $\quad 1^{\circ}$ Edicón BarcelonaEspaña. $717 p$

Coaquira Arratia, K. (2005). Perfil metabólico y peso vivo de llamas (Lama glama) machos alimentados con heno de cebada, alfalfa y kiri de quinua. Tesis de grado. Universidad Católica Boliviana "San Pablo". Unidad Académica Campesina de Tiahuanaco, Carrera Ingeniería Zootécnica. La Paz- Bolivia

Donald MC. P., Edwards, R., Greenhalgh, J. y Morgan, C. (1999). Nutrición animal. 5. a edición. Editorial Acribia, S.A. Zaragoza España. Pp. 271, 308, 45, 507

FAO (2005). La Organización de las Naciones Unidas para la Alimentación y la Agricultura. Situación actual de los camélidos sudamericanos en Bolivia

Garnica, J., Arocutipa, M. y Bravo, W. (2003). Componentes bioquímicos de la sangre de vicuñas en el altiplano peruano. En: Resúmenes III Congreso Mundial sobre Camélidos. Potosí. Bolivia

Gómez Piquer, J, (1992). Manual Práctico de Análisis Clínico en Veterinaria Primera edición. Mira Editores S. A. Zaragoza. Pp.184

Jones, R. (2001). Problemas de post-parto y lactancia. Consultada en octubre 2012. Disponible en: http://www.porcicultura.com/artículos

Kraft, H. Y Dierter, S. (1998). Métodos de laboratorio clínico en medicina veterinaria de mamíferos domésticos. 3 ra ed. Editorial Acribia, S.A. Zaragoza España. Pp. 49-67.

Kraft, W. y Durr, U. M. (2000). Diagnóstico de laboratorio clínico veterinaria. $4^{\text {ta }}$ ed. Editores Médicos, S.A. Gabriela mistral, 2. 28035 Madrid, Rafael de Casanova, 1. 
8950 esplugues de Llobregat (Barcelona). Pp.12, 156-157,216

Murray, E. Y Fowler, DVM. (1998). Medicine and surgery of South American Camelids. Llama, alpaca, vicuña y guanaco. $2^{\text {da }}$ ed. Iowa University Press. USA. Chapter

Gobierno Municipal De Curahuara De Carangas, (2007). PDM Plan de Desarrollo Municipal de Curahuara de Carangas. Provincia Sajama. Oruro -Bolivia

Quispe Chura Ynes S. (2007). Perfil metabólico y ganancia de peso vivo de llamas (Lama glama) alimentadas con tres raciones en época seca; Curahuara de Carangas-Departamento Oruro. Tesis de grado. Universidad Católica Boliviana "San Pablo". Unidad Académica Campesina de Tiahuanaco, Carrera Ingeniería Zootécnica. La Paz- Bolivia

Radostits, O. M. Gay, C., Blood, D. Hinchcliffet al., (2002). Medicina Veterinaria. 9na edición; Edición; Mc Graw-Hill INTERAMERICANA, S.A.U. Pp.84, 85

San Martin, F. (1999). Nutrición y Alimentación de los camélidos sudamericanos, pp. 9-35. In: Seminario de Reproducción y Nutrición de Camélidos. Escuela Militar de Ingeniería "Mcal. Antonio José de Sucre", Unidad Ejecutora del Proyecto de Camélidos (UNEPCA), Comunidad Andina de Fomento (CAF), Fondo de .desarrollo Campesino, Fondo Internacional de Desarrollo Agrícola (FIDA), XVI Congreso Panamericano de Ciencias Veterinarias. Universidad Técnica de Oruro (UTO), Escuela Militar de Ingeniería (EMI). Seminario 2. Santa Cruz De La Sierra, La Paz, Oruro, Noviembre 912, 1998. La Paz, Bolivia
Senasag Catastro Pecuario (2010). Servicio Nacional de Sanidad Agropecuaria e Inocuidad Alimentaria; Ministerio Desarrollo Rural y Tierras

Scholz, H. (2001). Control metabólico en ganado usando parámetros en sangre y leche. Memorias XXV Congreso Nacional de Buiatría, Veracruz, México. Pp.70-72

Studdert, B, Obe, D.C. (1994). P. V. Diccionario de Veterinaria Vol. I y ll, 1aㅡ Edición; Editorial Interamericana, S.A. de C.V., Mc.Graw-Hill. México. D.F. Pp.38, 516, 789

Ticona, B. E. (2009). Concentración de metabolitos y comportamiento de peso vivo en llamas (Lama glama) alimentadas con: paso natural y heno de cebada durante la gestación, postpartum y crías en turco-departamento de Oruro. Tesis de grado. Universidad Católica de "San Pablo". Carrera Ingeniería Zootécnica. La Paz- Bolivia

Van Saun, R J. (2004). Using a pooled sample technique for herd metabolic profile screening. In: Proceedings 12th Internacional Conference on Producction Diseases in Farm Animals. ICPD, July 19 22/2004 East Lansing, Michigan

Wattiaux, M. (2000). Metabolismo de Carbohidratos, Lípidos y Proteínas en

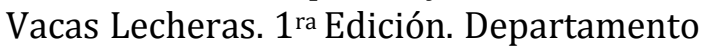
de Ciencias de Ganado Lechero. Universidad de Winconsin. Madisson, EEUU

Zapata, W. et al. (2001). Manual de química Sanguínea Veterinaria SIN 1680 -9335 de la piedra I Jaime Otero I. Lima - Perú 